\title{
How to choose a suitable intraabdominal pressure level during single-incision laparoscopic surgery in children
}

\author{
Xiaomin $\mathrm{HOU}^{1 *}$ (D), Peijuan $\mathrm{CHEN}^{2}$, Yu JIANG ${ }^{3}$
}

\begin{abstract}
Laparoscopic surgery has become a common procedure in pediatric patients. However, adverse hemodynamic changes such as the increase of intraabdominal pressure (IAP) may occur laparoscopic surgery. The aim of this study is find a method to set a suitable IAP level in children before laparoscopic surgery. From Jan 2012 to Dec 2014, data were collected from a total of 1776 children needing laparoscopic high ligation of hernia sac. A retrospective data analysis was performed using a new defined variant Index A which had information of age, body mass index (BMI) and duration of pneumoperitoneum. The blood pressures (SBP and DBP) and the $\mathrm{PaCO}_{2}$ were increased but SV showed no changes in patients after $\mathrm{CO}_{2}$ insufflation. The complications were found in 32 cases including 2 cases with subcutaneous emphysemarelated to the $\mathrm{CO}_{2}$ insufflation directly, 3 cases of respiratory infection, 5 cases of incision infection and 2 cases of urinary tract infection) and technique related. Furthermore, the risks of complications were negatively associated with the Index A. An IAP can be optimal set up in laparoscopic high ligation of hernia sac by using the Index A.
\end{abstract}

Keywords: laparoscopic surgery; intraabdominal pressure; pneumoperitoneum; $\mathrm{CO}_{2}$ insufflation pressure.

Practical Application: Control of an intraabdominal pressure in laparoscopic high ligation of hernia sac using the Index A.

\section{Introduction}

Nowadays, laparoscopic surgery has become a worldwide common daily-performed procedure in pediatric patients (Gupta \& Singh, 2009). Being a minimal access procedure, it is usually assisted by a pneumoperitoneum, for which carbon dioxide $\left(\mathrm{CO}_{2}\right)$ insufflation is preferred by most laparoscopists because of its safety, cost and convenience (Tam, 2000). However, it has been also reported that laparoscopic surgery is associated with many clinical complications including gas embolism, cardiovascular compromise, and hypercapniain children (Chen et al., 1996; Bax \& Van der Zee, 1999; Esposito et al., 2000). The pathophysiological disturbances induced by $\mathrm{CO} 2$ insufflation or pneumoperitoneum were reviewed in a previous study (Hackam \& Rotstein, 1998).

A normal intraabdominal pressure (IAP) should be 5-7 $\mathrm{mmHg}$ in children (De Keulenaer et al., 2009). For laparoscopic procedure, IAP levels within $8-12 \mathrm{mmHg}$ are acceptable for children older than one year (Mishchuk et al., 2016). Moreover, IAP level of $12 \mathrm{mmHg}$ has been reported to be associated with decreased cardiac index and hypokinesis of left ventricular in children (Sakka et al., 2000). Some other factors such as duration of surgery, position of patients, etc. could lead to pathophysiological changes in the surgeries. In the present study, we tried to find an optimal IAP level which provided enough visual space and induced fewer complications in pediatric laparoscopic surgeries.

\section{Methods}

\subsection{Laparoscopic surgery}

This experiment was done in Nanfang Hospital of Southern Medical University which is one of the top three biggest medical centers in Guangdong Province, and has more than 2200 beds and about over 1000 outpatients daily. In our department, more than 800 paediatric laparoscopic surgeries including intestinal procedures, urological procedures, diaphragmatic hernia repair, appendectomy, and cholecystectomy, have been performed by paediatric surgeons yearly. From Jan 2012 to Dec 2014, the patients (0.9-12 years old) treated with laparoscopic high ligation of hernia sac were recruited in this study.

All patients were positioned supine, often in the Trendelenberg position. In addition, they had no diagnosed cardiovascular and pulmonary disease before laparoscopic surgery. The systolic blood pressure (SBP), diastolic blood pressure (DBP), stroke volume (SV) and arterial partial pressure of $\mathrm{CO}_{2}\left(\mathrm{PaCO}_{2}\right)$ were recorded every $10 \mathrm{~min}$ from the baseline (T0), which was defined as a time point (TP) five minu before $\mathrm{CO}_{2}$ insufflation. T1 (5 min after insufflations), T2 (15 min after insufflation), T3 (end of insufflation) were also recorded (Table 1).

Furthermore, the complications were defined as all adverse effects related to pneumoperitoneum or operation in $30 \mathrm{~d}$ during or after operation, such as carbon dioxide embolism, barotraumas, respiratory acidosis, hypertension, hypotension, arrhythmias, 
hypercapnia (or hypoxemia), deep venous thrombosis (DVT), subcutaneous emphysema, etc. The risk factors that could increase or decrease the risk of adverse effects of pneumoperitoneum possibly were also recorded and considered as covariant in the statistical model.

\subsection{Logistic analysis}

In the present study, logistic analysis was performed to explore the relative risk (RR) of various IAP specified by an Index $\mathrm{A}$, which was calculated as a ratio between duration of pneumoperitoneum (min), age (year) and BMI of patients (Index A=Age ${ }^{\star} \mathrm{BMI} /$ duration). The duration of pneumoperitoneum would be expressed using rounding value, such as $30 \mathrm{~min}, 40 \mathrm{~min}$, $50 \mathrm{~min}, 60 \mathrm{mi}$ and $70 \mathrm{~min}$. The index A was grouped under three categories (1: 1.0-2.5, 2: 2.6-3.9, 3: 4.0-5.9) to make sure that no big difference in patients' number between each category. The IAP was classified into five groups according to their pressure values

Table 1. The data collection plan in the laparoscopic operation.

\begin{tabular}{ccccc}
\hline TP & T0 & T1 & T2 & T3 \\
\hline Timeline & $\begin{array}{c}5 \text { minutes } \\
\text { before } \\
\text { insufflation } \\
\text { (Baseline) }\end{array}$ & $\begin{array}{c}5 \text { minutes } \\
\text { after } \\
\text { insufflation }\end{array}$ & $\begin{array}{c}\text { 15 minutes } \\
\text { after } \\
\text { insufflation }\end{array}$ & $\begin{array}{c}\text { End of } \\
\text { Insufflation }\end{array}$ \\
$\mathrm{BP}$ & $\mathrm{x}$ & $\mathrm{x}$ & $\mathrm{x}$ & \\
$\mathrm{PaCO}_{2}$ & $\mathrm{x}$ & $\mathrm{x}$ & $\mathrm{x}$ & $\mathrm{x}$ \\
$\mathrm{SV}$ & $\mathrm{x}$ & $\mathrm{x}$ & $\mathrm{x}$ & $\mathrm{x}$ \\
\hline
\end{tabular}

Table 2. Baseline characteristics of study patients.

\begin{tabular}{lc}
\hline $\mathrm{N}$ & 1776 \\
Age (years) & $0.9-12.0$ \\
$\mathrm{BMI}$ & $14.81-27.98$ \\
Duration of pneumoperitoneum (minutes) & $34-67$ \\
IAP (mmHg) & $6-12$ \\
Index A & $1.3-5.8$ \\
Complications & 32 \\
\hline
\end{tabular}

$\mathrm{N}$ : the total sample of collected patients in the present study. including 6.0-7.9 mmHg (group 1), 8.0-9.9 mmHg (group 2), 10.0-10.9 $\mathrm{mmHg}$ (group 3), 11.0-11.9 $\mathrm{mmHg}$ (group 4), and 12.0-12.9mmHg (group 5). The significant level was set at 0.05. All the statistical analysis was performed with Statistical Analysis Software Version 9.3 (SAS, SAS Institute Inc., NC, USA).

\section{Results}

\subsection{Baseline characteristics of patients}

In the present study, the data of a total of 1776 children such as age, BMI, duration of pneumoperitoneum, Index A and complications were collected. As shown in Table 2, the age of children was ranged from 0.9 to 12.0 years $(6.59 \pm 2.41)$, and the BMI was between 14.81 and 27.98 (19.43 \pm 7.34 ). The shortest duration of pneumoperitoneum was $34 \mathrm{~min}$ while the longest one was $67 \mathrm{~min}$. The Index A was ranged from 1.3 to $5.8(3.72 \pm 1.28)$.

\subsection{Changes of blood pressures of patients, the $\mathrm{PaCO}_{2}$ and $S V$ in patients during the operation}

The blood pressures of patients (SBP and DBP), the $\mathrm{PaCO}_{2}$ and $\mathrm{SV}$ were measured during the operation at stages of T0, T1,T2, T3. It was suggested that, compared to T0, the blood pressures of patients (SBP and DBP) and the $\mathrm{PaCO}_{2}$ increased after $\mathrm{CO}_{2}$ insufflation in T1, T2 and T3 during the surgery $(P<0.05)$. Most of them had been statistical significant elevated from the baseline measured value. However, the SV decreased a little after $\mathrm{CO}_{2}$ insufflation but there was differce between T0 and T1, T2, T3 $(P>0.05)$ (Table 3$)$.

\subsection{Complications of patients}

Overall, a total of 32 adverse effects were detected in this study and the percentage of complications was $1.8 \%$. The distribution of them was shown in Table 4. It was found that, based on IAP classification, among 32 complications, 6 (1.3\%), 6 (1.3\%), 5 (1.7\%), 7 (2.3\%) 8 (2.9\%) blonged to group 1, group 2, group 3 , group 4 , and group 5, respectively. In addition, it ranged from $1.0 \%$ to $4.7 \%$ by varied IAP and Index A (Table 4 ). An interesting

Table 3. Descriptive analysis of blood pressure, $\mathrm{PaCO}_{2}$ and $\mathrm{SV}$ during the operation.

\begin{tabular}{ccccc}
\hline & T0 & T1 & T2 & T3 \\
\hline SBP $(\mathrm{mmHg})$ & $93.00 \pm 6.89$ & $127.00 \pm 7.65^{*}$ & $132.00 \pm 7.14^{*}$ & $131.50 \pm 6.89^{*}$ \\
DBP (mmHg) & $69.50 \pm 2.81$ & $83.00 \pm 3.57^{*}$ & $83.00 \pm 4.08^{*}$ & $72.50 \pm 2.30$ \\
$\mathrm{PaCO}_{2}(\mathrm{mmHg})$ & $36.25 \pm 3.48$ & $38.66 \pm 3.79$ & $40.02 \pm 3.52^{*}$ & $40.13 \pm 3.26^{*}$ \\
SV $(\mathrm{mL})$ & $22.00 \pm 1.53$ & $20.00 \pm 1.53$ & $20.50 \pm 1.68$ & $20.40 \pm 1.79$ \\
\hline
\end{tabular}

*Statistical significant different from T0 value.

Table 4. Descriptive analysis of complications among 1776 patients.

\begin{tabular}{|c|c|c|c|c|c|c|c|c|c|c|c|c|}
\hline \multirow{2}{*}{$\begin{array}{c}\text { IAP } \\
\text { Index A }\end{array}$} & \multicolumn{2}{|c|}{1} & \multicolumn{2}{|c|}{2} & \multicolumn{2}{|c|}{3} & \multicolumn{2}{|c|}{4} & \multicolumn{2}{|c|}{5} & \multicolumn{2}{|c|}{ Total } \\
\hline & $\mathrm{n}(\%)$ & $\mathrm{N}$ & $\mathrm{n}(\%)$ & $\mathrm{N}$ & $\mathrm{n}(\%)$ & $\mathrm{N}$ & $\mathrm{n}(\%)$ & $\mathrm{N}$ & $\mathrm{n}(\%)$ & $\mathrm{N}$ & $\mathrm{n}(\%)$ & $\mathrm{N}$ \\
\hline 1 & $2(1.3 \%)$ & 152 & $2(1.3 \%)$ & 150 & $3(3.4 \%)$ & 89 & $3(3.2 \%)$ & 94 & $4(4.7 \%)$ & 86 & $14(2.5 \%)$ & 571 \\
\hline 2 & $2(1.4 \%)$ & 147 & $2(1.3 \%)$ & 154 & $1(1.0 \%)$ & 98 & $2(2.0 \%)$ & 101 & $2(2.2 \%)$ & 91 & $9(1.5 \%)$ & 591 \\
\hline 3 & $2(1.2 \%)$ & 161 & $2(1.4 \%)$ & 142 & $1(1.0 \%)$ & 105 & $2(1.8 \%)$ & 109 & $2(2.1 \%)$ & 97 & $9(1.5 \%)$ & 614 \\
\hline Total & $6(1.3 \%)$ & 460 & $6(1.3 \%)$ & 446 & $5(1.7 \%)$ & 292 & $7(2.3 \%)$ & 304 & $8(2.9 \%)$ & 274 & $32(1.8 \%)$ & 1776 \\
\hline
\end{tabular}

$\mathrm{N}$ : amount of patients in subgroup; $\mathrm{n}$ : the number of complication in subgroup. 
Table 5. Relative risks (RR) of complications.

\begin{tabular}{|c|c|c|c|c|c|}
\hline \multirow{2}{*}{ IAP } & \multirow{2}{*}{ Group } & 2 & 3 & 4 & 5 \\
\hline & & RR (95\% CI) & RR (95\% CI) & RR (95\% CI) & RR (95\% CI) \\
\hline \multirow[t]{2}{*}{ Index A } & 1 & $1.00(0.82-3.42)$ & $2.62(1.24-5.05)$ & $2.46(1.04-5.89)$ & $3.74(1.55-5.17)$ \\
\hline & 2 & $0.96(0.47-2.37)$ & $0.77(0.11-2.66)$ & $1.43(0.88-6.24)$ & $1.57(0.87-6.99)$ \\
\hline
\end{tabular}

Bold means statistical significant. RR(95\%CI): Relative risk and its 95\% confidence interval.

finding in the present study was that there were only two adverse effects (subcutaneous emphysema) related to the $\mathrm{CO}_{2}$ insufflation directly. Most of the complications were postoperative infection ( 3 cases of respiratory infection, 5 cases of incision infection and 2 cases of urinary tract infection) and technique related.

\subsection{Results of logistic regression analysis}

Univariate logistic regression analyses were performed to estimate relative risks of complications between IAP groups specified by Index A. As demonstrated in Table 5, the risk of complication seemed to have no changes for IAP at 8 and $9 \mathrm{mmHg}$. However, when IAP was more than $10 \mathrm{mmHg}$, a tendency could be observed that the risk ratio (RR) elevated with the increase of IAP. Particularly, when Index A was between 1.0 and 2.5, the patients had increased risks of 1.62, 1.46 and 2.74 for IAP groups at $10 \mathrm{mmHg}, 11 \mathrm{mmHg}$ and $12 \mathrm{mmHg}$, respectively.

The results also showed that the smaller Index A was, the higher the risk of clinical complication was, especially when the IAP was higher. Nevertheless, the risk of complication seemed to be the same when IAP value was less than $9 \mathrm{mmHg}$. Furthermore, when Index A was not less than 2.6, the risk of complication seemed to be the same as well (Table 5).

\section{Discussion}

The present research was a data analysis based on 1776 children's record of laparoscopic surgical procedures to study the association between IAP and adverse effects of $\mathrm{CO}_{2}$ pneumoperitoneum, trying to find a method to estimate the safe IAP before pneumoperitoneum to decrease risk of complications.

As we know, a higher intraabdominal pressure (IAP) would contribute to better visualization of the anatomical structures and better manipulation of instruments. However, it could also lead to lots of pathophysiological changes on hosts, like respiratory changes, cardiovascular changes. Just as observed in our study, apart from the SV, the blood pressure and $\mathrm{PaCO}_{2}$ were increased in $\mathrm{CO}_{2}$ insufflated patients compared to pre- $\mathrm{CO}_{2}$ insufflated patients and the differences between pre- $\mathrm{CO}_{2}$ insufflation group and post- $\mathrm{CO}_{2}$ insufflation groups were statistically significant. The SV was reported to be decreased by laparoscopic surgery (Wahba et al., 1995). Some further studies showed that the SV had a more considerable decrease in the $15 \mathrm{mmHg}$ group and no significant hemodynamic change was observed in $10 \mathrm{mmHg}$ or $7 \mathrm{mmHg}$ group (Dexter et al., 1999; Perry et al., 2003). In this study, a significant hemodynamic change in blood pressure and $\mathrm{PaCO}_{2}$ was also observed in five IAP groups but no changes in SV was detected in five groups $(p>0.05)$.
According to the results, pathophysiological changes were unavoidable by the pneumoperitoneum in every level of IAP and happened instantly after $\mathrm{CO}_{2}$ insufflation. However, the clinical complications could be unlikely observed in each patient. An interesting finding in the present study was that there were only two adverse effects (subcutaneous emphysema) related to the $\mathrm{CO}_{2}$ insufflation directly. In addition to those two cases associated directly with pneumoperitoneum, many postoperative infections might be pneumoperitoneum related because of immunologic depress induced by $\mathrm{CO}_{2}$ insufflation (Ellström et al., 1996; Redmond et al., 1994; Lippert et al., 2002).

In the present study, the Index A was designed as a new covariate, including the information on the factors that could increase or decrease the risks of adverse effects for pneumoperitoneum. Patient positioning might affect pathophysiological changes of human beings as well (Joris et al., 1993; Kelman et al., 1972). However, it is difficult to quantize the clinical impact of varied position (Trendelenburg and reverse Trendelenburg position), so only the patients with Trendelenburg were recruited. According to the definition, the duration has a negative association with Index $\mathrm{A}$ and the longer time the pneumoperitoneum takes, the smaller the Index A is. Compared with the control group, those three significantly elevated RRs were only found in the group 1 of Index A (1.0-2.5). These results provided some suggestions with good clinical practice meaning, that a suitable IAP level could be chosen according to Index A values. If Index $\mathrm{A}$ is more than 2.6, there is no worry about a complication by each IAP level for children. When Index A is less than 2.6, the risks of complications will be increased and the IAP level should be lower. The index A is negatively related to the risks of complications in patients. Although it seems easy to choose IAP level according to the Index A, there is still a problem to calculate the Index A before operation since the duration is unknown before the operation. Surgeon should estimate the duration of $\mathrm{CO}_{2}$ insufflation according to his/her experience before laparoscopic operation. Another issue, which seemed to be limitation of the study, is the consistence in patients and surgeons. There were two attending surgeon in the studies, and we believe they do do the operations in the same level and it will not lead to problem drawing conclusions.

It is first time to define an Index A used to choose an optimal IAP level before laparoscopic operation among children with high ligation of hernia sac, which will make the laparoscopic surgeries much more safety. Although it is just simple index, we hope other collegers in the world could do more works making it more practise in future. 


\section{Acknowledgements}

The present study was initiated and sponsored by the Dean fund of Nanfang Hospital, the Southern Medical University, China (No. H2015002).

\section{References}

Bax, N. M., \& Van der Zee, D. C. (1999). Complications in laparoscopic surgery in children. In N. M. Bax, K. E. Georgeson, A. Najmaldin \& J. S. Valla (Eds.), Endoscopic surgery in children (pp. 57-68). Berlin: Springer-Verlag. http://dx.doi.org/10.1007/978-3-642-59873-9_41.

Chen, M. K., Schropp, K. P., \& Lobe, T. E. (1996). Complications of minimal-access surgery in children. Journal of Pediatric Surgery, 31(8), 1161-1165. http://dx.doi.org/10.1016/S0022-3468(96)901098. PMid:8863256.

De Keulenaer, B. L., De Waele, J. J., Powell, B., \& Malbrain, M. L. (2009). What is normal intra-abdominal pressure and how is it affected by positioning, body mass and positive end-expiratory pressure? Intensive Care Medicine, 35(6), 969-976. http://dx.doi.org/10.1007/ s00134-009-1445-0. PMid:19242675.

Dexter, S. P. L., Vucevic, M., Gibson, J., \& McMahon, M. J. (1999). Hemodynamic consequence of high- and low-pressure capnoperitoneum during laparoscopic cholecystectomy. Surgical Endoscopy, 13(4), 376-381. http://dx.doi.org/10.1007/s004649900993. PMid:10094751.

Ellström, M., Bengtsson, A., Tylman, M., Haeger, M., Olsson, J. H., \& Hahlin, M. (1996). Evaluation of tissue trauma after laparoscopic and abdominal hysterectomy: measurement of neutrophil activation and release of interleukin-6, cortisol and C-reactive protein. Journal of the American College of Surgeons, 182(5), 423-430. PMid:8620278.

Esposito, C., Montupet, P., Amici, G., \& Desruelle, P. (2000). Complications of laparoscopic antireflux surgery in childhood. Surgical Endoscopy, 14(7), 622-624. http://dx.doi.org/10.1007/ s004640000143. PMid:10948297.

Gupta, R., \& Singh, S. (2009). Challenges in Paediatric Laparoscopic Surgeries. Indian Journal of Anaesthesia, 53(5), 560-566. PMid:20640106.

Hackam, D. J., \& Rotstein, O. D. (1998). Host response to laparoscopic surgery: mechanisms and clinical correlates. Canadian Journal of Surgery, 41(2), 103-111. PMid:9575992.
Joris, J., Banache, M., Bonnet, F., Sessler, D. I., \& Lamy, M. (1993). Clonidine and ketanserin both are effective treatment for postanesthetic shivering. Anesthesiology, 79(3), 532-539. http:// dx.doi.org/10.1097/00000542-199309000-00017. PMid:8363079.

Kelman, G. R., Swappy, G. H., Smith, I., Benzie, R. J., \& Gordon, N. L. M. (1972). Cardiac output and arterial blood-gas tension during laparoscopy. British Journal of Anaesthesia, 44(11), 1155-1162. http:// dx.doi.org/10.1093/bja/44.11.1155. PMid:4265051.

Lippert, H., Koch, A., Marusch, F., Wolff, S., \& Gastinger, I. (2002). Open vs. laparoscopic appendectomy. Der Chirurg, 73(8), 791-798. http://dx.doi.org/10.1007/s00104-002-0500-y. PMid:12425155.

Mishchuk, V., Lerchuk, O., Dvorakevych, A., \& Khomyak, V. (2016). Features of respiratory support during laparoscopic correction of inguinal hernias in children. Videosurgery and Other Miniinvasive Techniques, 11(2), 55-59. http://dx.doi.org/10.5114/wiitm.2016.59837. PMid:27458483.

Perry, Y., Reissman, P., Blumental, M., Lyass, S., \& Pizov, R. (2003). Pressure related hemodynamic effects of $\mathrm{CO}_{2}$ pneumoperitoneum in a model of acute cardiac failure. Journal of Laparoendoscopic \& Advanced Surgical Techniques Part A., 13(6), 341-347. http://dx.doi. org/10.1089/109264203322656388. PMid:14733695.

Redmond, H. P., Watson, R. W., Houghton, T., Condron, C., Watson, R. G., \& Bouchier-Hayes, D. (1994). Immune function in patients undergoing open vs laparoscopic cholecysterctomy. Archives of Surgery (ChicAug, Ill.), 129(12), 1240-1246. http://dx.doi.org/10.1001/ archsurg.1994.01420360030003. PMid:7986152.

Sakka, S. G., Huettemann, E., Petrat, G., Meier-Hellmann, A., Schier, F., \& Reinhart, K. (2000). Transoesophageal echocardiographic assessment of haemodynamic changes during laparoscopic herniorrhaphy in small children. British Journal of Anaesthesia, 84(3), 330-334. http:// dx.doi.org/10.1093/oxfordjournals.bja.a013434. PMid:10793591.

Tam, P. K. H. (2000). Laparoscopic surgery in children. Archives of Disease in Childhood, 82(3), 240-243. http://dx.doi.org/10.1136/ adc.82.3.240. PMid:10685931.

Wahba, R. W., Beique, F., \& Kleiman, S. J. (1995). Cardiopulmonary function and laparoscopic cholecystectomy. Canadian Journal of Anaesthesia, 42(1), 51-63. http://dx.doi.org/10.1007/BF03010572. PMid:7889585. 